\title{
International Tourism Marketing: An Analysis on Xinjiang Uygur Autonomous Region (XUAR) of China
}

\author{
Dilidaer Mulati ${ }^{1}$, Ilkay Karaduman ${ }^{2}$ \\ ${ }^{I}$ (Social Sciences Institute, Istanbul Aydin University, Turkey) \\ ${ }_{2}^{2}$ (Faculty of Economics and Administrative Sciences, Istanbul Aydin University, Turkey)
}

\begin{abstract}
As XUAR international tourism industry is improving gradually, we should see there are still serious problems in its industrial structure performance. With shift-share method, Pearson Correlation method and Principal component method, based on data of XUAR international tourism foreign exchange incomes from 2006 to 2015, this paper empirically analyzes each sector of XUAR international tourism and its industrial structure performance, as well as problems in sectors of transportation, sightseeing, accommodation, cater, commodity sales and entertainment. Meanwhile this paper also puts forward solutions to increase the benefit of XUAR international tourism industry.
\end{abstract}

Keywords: International tourism, XUAR, Tourism Marketing

\section{Introduction}

International tourism is an important part of tourism industry and international service trade, which plays a more important role in promoting global economic development, so the development of international tourism has gained more attention around the world. Per the UNWTO Tourism Highlights by United Nations World Tourism Organization ${ }^{[1]}$, the number of international visitors in 2015 increased by $4.6 \%$ to 1.186 billion compared with the number of 2014. In 2014, more than 52 million tourists (overnight visitors) traveled abroad. The total revenue generated by international travelers for accommodation, catering, entertainment, shopping and other services in 2015 was approximately $\$ 1.232$ billion, increasing by $3.6 \%$ due to the foreign exchange rate fluctuations and inflation. International tourist arrivals increased by $4.4 \%$ or 1.184 million in 2015.In addition to international tourism revenue (travel expenses of international balance of payments), international tourism also generated $\$ 210$ billion in international export transport services for non-residential visitors, bringing tourism exports revenues of $\$ 1.4$ trillion or an average daily income of $\$ 4$ billion ${ }^{[2]}$.

United Nations World Tourism Organization has released the UNWTO Tourism Highlights ${ }^{[3]}$, which shows World Tourism Organization is very concerned about the emerging destinations, and economies and destinations are mentioned frequently. Chinese elements continue to be the focus of attention.Per Annual Report on China 's Inbound Tourism Development 2016 from China Tourism Research Institute ${ }^{[4]}$, in 2015 China received 13,382.04 million inbound tourists, an increase of 4.14\%. In 2005, foreign exchange revenue of inbound tourism reached $\$ 113.65$ billion, and tourism service trade surplus reached $\$ 9.15$ billion. In 2015 , China receives 568.857 billion overnight visitors, an increase of $2.30 \%$.The gross market size ranked fourth in the world, following France, United States and Spain. As the concept of new Silk Road has been proposed, XUAR has taken actions in their own specialties - the success organization of International Conference on Tourism Development on the Silk Road, and Urumqi Declaration with 14 other countries along the Silk Road. XUAR has set up six oversea sales centers in Kazakhstan, Russia, Dubai and other countries. We have cooperated closely with Kazakhstan and other neighboring countries for tourism exchanges and more convenient visa policy -the policy of visa free for tourism team of 3-50 persons will soon be implemented. However, compared with the rapid development of the global tourism industry, growth of XUAR international tourism industry is left far behind. Therefore, now, it is of great significance to grasp consumption structure of XUAR international market, to establish marketing strategy and to enhance the international competitiveness of XUAR.

\section{Analysis On Consumption Structure Of XUAR International Tourism}

Simply, tourism can be defined as the practice of traveling for recreation and with a point of management the definition can be such as the management process of tourists and tourism related businesses ${ }^{[5]}$. In the literature, tourism marketing has been researched in detail from its past to its present and future ${ }_{[6][7][8][9][10][11][12][13]}$. Dwyer, et al. found tourism has been commonly recognized that it is neither a single industry nor a single market. In Tourism is a social industry with strong integrity and intrinsic relevance which composed of elements of sightseeing, catering, accommodation, entertainment and Commodity sales ${ }^{[14]}$.An analysis on consumption structure of international tourist market is instructive and meaningful to take effective measures to solve tough problems, optimize the structure of the tourism industry and improve economic level of tourism industry. 


\subsection{Deviation of Structural Benefit of International Tourism Industry Shift- Share Analysis}

Shift-share analysis is a relatively simple and widely used technique for describing regional economic growth and measuring policy effects over time ${ }^{[15]}$.According to international tourism income composition of XUAR in the period of 2006-2014 (table 1), using the shift share analysis of the international tourism industry (based on figures of 2013). Transportation, sightseeing, accommodation, catering, commodity sales and entertainment are considered as the influencing factors of foreign exchange earnings of international tourism. ${ }^{[16]}$.

Table 1: The Composition of XUAR International Tourism Revenue in the Period of 2006-2014 (\%)

\begin{tabular}{|c|c|c|c|c|c|c|}
\hline Year & Transportation & Sightseeing & Accommodation & Catering & Commodity Sales & Entertainment \\
\hline 2006 & 24.3 & 3.6 & 9.1 & 5 & 40 & 6.7 \\
\hline 2007 & 15.5 & 2 & 6.8 & 5.5 & 52.5 & 1.6 \\
\hline 2008 & 23.1 & 3.2 & 7.8 & 5.6 & 47.4 & 1 \\
\hline 2009 & 22.1 & 5.3 & 8 & 6.1 & 46.2 & 1.6 \\
\hline 2010 & 25.9 & 4.8 & 8.1 & 5.5 & 36.3 & 1.4 \\
\hline 2011 & 24.3 & 3.2 & 7.7 & 4.3 & 38 & 0 \\
\hline 2012 & 38.3 & 5.4 & 12.2 & 5 & 20 & 7.1 \\
\hline 2013 & 35.9 & 6.4 & 12.3 & 6.1 & 19.8 & 6.2 \\
\hline 2014 & 39.4 & 7 & 11.9 & 7.3 & 15.7 & 6.4 \\
\hline
\end{tabular}

According to the shift-share method, the equation of XUAR tourism economic growth rate is shown as follows: $Y_{i o}$ is foreign exchange income of XUAR tourism industry (i) in base-period; $Y_{i t}$ is foreign exchange income of XUAR tourism industry (i) in a certain period $(\mathrm{t}) ; \mathrm{C}_{\mathrm{io}}$ is the cumulative foreign exchange earnings of the whole tourism industry (i) from the base period; $C_{i t}$ is foreign exchange income of XUAR tourism industry (i) in period $(t) ; C_{o}$ is tourism foreign exchange earnings of the entire Chinese tourism industry in base period; $C_{t}$ is foreign exchange income of Chinese tourism industry in a certain period $(\mathrm{t})$; so $\mathrm{R}_{\mathrm{i}}$, foreign exchange earnings growth rate of XUAR tourism industry (i) is shown as follow:

$$
\begin{gathered}
\mathrm{R}_{\mathrm{i}}=\left(\mathrm{Y}_{\mathrm{it}}-\mathrm{Y}_{\mathrm{io}}\right) / \mathrm{Y}_{\mathrm{io}}=\mathrm{U}_{\mathrm{i}}+\mathrm{V}_{\mathrm{i}}+\mathrm{W}_{\mathrm{i}} \\
\mathrm{U}_{\mathrm{i}}=\left(\mathrm{C}_{\mathrm{t}}-\mathrm{C}_{\mathrm{o}}\right) / \mathrm{C}_{\mathrm{o}} * 100 \% \\
\mathrm{~V}_{\mathrm{i}}=\left(\mathrm{C}_{\mathrm{it}} / \mathrm{C}_{\mathrm{io}}-\mathrm{C}_{\mathrm{t}} / \mathrm{C}_{\mathrm{o}}\right) / * 100 \% \\
\mathrm{~W}_{\mathrm{i}}=\left(\mathrm{Y}_{\mathrm{it}} / \mathrm{Y}_{\mathrm{io}}-\mathrm{C}_{\mathrm{it}} / \mathrm{C}_{\mathrm{io}}\right) / * 100 \%
\end{gathered}
$$

In those equations: Ui reflects the tourism industry growth rate; $\mathrm{V}_{\mathrm{i}}$ reflects the efficiency in the tourism industry (i): when $\mathrm{V}_{\mathrm{i}}>0$, the tourism industry sector is growing faster than the average growth rate of the whole Chinese tourism industry, and the efficiency of the sector is advantageous; $\mathrm{W}_{\mathrm{i}}$ is the advantage of XUAR tourism industry (i) compared with the sector (i) nationwide. When $\mathrm{W}_{\mathrm{i}}>0$, the greater the value of XUAR tourism industry the more advantages it has; when $\mathrm{W}_{\mathrm{i}}<0$, the smaller the value is the less advantages it has. Take year 2013 as the base period and based on Xinjiang Statistical Yearbook (2013 and 2014), the values of $U_{i}, V_{i}$,

\begin{tabular}{|c|c|c|c|c|c|c|c|}
\hline \multirow{2}{*}{$\begin{array}{l}\text { Sector } \\
\text { Year }\end{array}$} & \multicolumn{2}{|c|}{$\begin{array}{l}\text { Tourism income structure } \\
\text { of China (Billion USD) }\end{array}$} & \multicolumn{2}{|c|}{$\begin{array}{l}\text { Tourism income structure } \\
\text { of XUAR(Million USD) }\end{array}$} & $\begin{array}{l}\text { Industry } \\
\text { component of }\end{array}$ & $\begin{array}{l}\text { Industry structure } \\
\text { component }\end{array}$ & $\begin{array}{l}\text { Competitivene } \\
\text { ss component }\end{array}$ \\
\hline & 2013 & 2014 & 2013 & 2014 & \multirow[t]{8}{*}{10.16} & 2014 & 2014 \\
\hline Tourism & 51.664 & 56.915 & 585.02 & 497.04 & & - & - \\
\hline Transportation & 17.457 & 19.595 & 210.02 & 195.83 & & 2.0835 & -19.0037 \\
\hline Sightseeing & 3.092 & 3.254 & 37.44 & 34.79 & & -4.9244 & -12.3173 \\
\hline Accommodation & 5.976 & 6.95 & 71.96 & 59.15 & & 6.1348 & -34.1001 \\
\hline Catering & 4.128 & 4.828 & 35.69 & 36.28 & & 6.7936 & -15.3042 \\
\hline Commodity sales & 11.182 & 11.328 & 115.83 & 78.04 & & -8.8581 & -33.9311 \\
\hline Entertainment & 3.591 & 3.674 & 36.27 & 31.81 & & -7.8524 & -14.6080 \\
\hline
\end{tabular}
Wi of the international tourism industry in 2014 can be calculated (table 2) ${ }^{[17]}$.

Table 2: Structural Benefit Deviation of International Tourism Industry-- Shift-Share Analysis (Base Period 2013)

According to data in table 2, it can be concluded that in tourism industry of China, sectors with better revenue include catering, accommodation and transportation. However, there is no advantages of the tourism sector in XUAR compared with the whole industry of China.

\subsection{Pearson Correlation Analysis}

In order to evaluate the rationality of the effect of each sector to the international tourism foreign exchange income, here we have done the Pearson correlation analysis on international tourism industry and sectors that affect international tourism industry ${ }^{[18]}$. Using Pearson correlation analysis method of SPSS, the results are as follows: 
Table 3: Correlations Among Sections of Tourism Industry

\begin{tabular}{|l|l|l|}
\hline Sectors & Pearson Correlation & Sig. (2-tailed) \\
\hline Transportation & $.958^{* *}$ & 0 \\
\hline Sightseeing & $.927^{* *}$ & 0 \\
\hline Accommodation & $.955^{* *}$ & 0 \\
\hline Catering & $.937^{* *}$ & 0 \\
\hline Commodity Sales & .558 & 0.118 \\
\hline Entertainment & $.748^{*}$ & 0.02 \\
\hline$* *$ Correlation is significant at the 0.01 level (2-tailed). \\
\hline$*$ Correlation is significant at the 0.05 level (2-tailed). \\
\hline
\end{tabular}

Generally, the four-level classification method is used for judging the relationship between variables: the absolute value of correlation below 0.3 means weak correlation; 0.3-0.5 means low linear correlation; 0.50.8 means significant correlation; number more than 0.8 means high correlation. It can be seen from table 5 that the coefficient of transportation and international tourism industry is 0.958 , the coefficient of sightseeing and the international tourism industry is 0.927 , accommodation 0.955 , catering 0.937 , entertainment 0.748 and sales of goods 0.558 , which means that each sector has significant positive correlation with the international tourism industry. The values of transportation, sightseeing, accommodation and catering are more than 0.8 , indicating that these four factors are the most important factor in determining the number of foreign exchange earnings of international tourism.

\subsection{Principal Component Analysis}

\subsubsection{Basic Principle of Principal Component Analysis}

Principal component analysis (PCA) is an algorithm to simplify the original data set by reducing the dimension of data sets. The main idea of the algorithm is to repeatedly observe an object and do comprehensive process of several correlated random variables, and then the obtained one or several comprehensive indexes can replace the original variables. The indexes can represent characteristics of the object independently and, at the same time, can retain the integrity of the original information. And principal components analysis is classified among the descriptive methods analyzing interdependencies between variables. Hence, there are no dependent variables and independent variables, it is so important to combine the interdependence between the variables ${ }^{[19]}$. The fundamental transformation can be shown as follow:

$$
\begin{aligned}
& {\left[\begin{array}{l}
P C_{1} \\
P C_{2} \\
\cdots \\
P C_{m}
\end{array}\right]=\left[\begin{array}{cccc}
a_{11} & a_{12} & \cdots & a_{1 p} \\
a_{21} & a_{22} & \cdots & a_{2 p} \\
\cdots & \cdots & \cdots & \cdots \\
a_{m 1} & a_{\mathrm{m} 2} & \cdots & a_{m p}
\end{array}\right]\left[\begin{array}{l}
X_{1} \\
X_{2} \\
\cdots \\
X_{p}
\end{array}\right]} \\
& {\left[\begin{array}{llll}
a_{11} & a_{12} & \cdots & a_{1 p} \\
a_{21} & a_{22} & \cdots & a_{2 p} \\
\cdots & \cdots & \cdots & \cdots \\
a_{m 1} & a_{\mathrm{m} 2} & \cdots & a_{m p}
\end{array}\right]}
\end{aligned}
$$

is a weighted coefficient matrix, and $m \leq p$. PCi means the the order of principal component of the original eigenvector. According to equation (1), the principal component matrix is a linear combination of original feature vectors. In addition, parameters in equation (1) should satisfy the following conditions:

(a) $a_{i 1}^{2}+a_{i 2}^{2}+\ldots+a_{i p}^{2}=2, i=1,2,3, \ldots, m$;

(b) $\operatorname{Cov}\left(P C_{i}, P C_{j}\right)=0, j<i, i, j=1,2, \ldots, m$, That is, principal component are orthogonal with each other.

\subsubsection{Calculation Steps of PCA}

To calculate relation matrix

$$
N=\left\{\begin{array}{cccc}
\kappa_{11} & \kappa_{12} & \ldots & \kappa_{1 p} \\
\kappa_{21} & \kappa_{22} & \ldots & \kappa_{2 p} \\
. . & . . & & . . \\
\kappa_{p 1} & \kappa_{p 2} & \ldots & \kappa_{p p}
\end{array}\right.
$$

In equation (2), $(\mathrm{i}, \mathrm{j}=1,2, \ldots, \mathrm{p})$ is correlation index of original variables $\mathrm{x}_{\mathrm{i}}$ and $\mathrm{x}_{\mathrm{j}}$, the equation is as follow: 


$$
r_{i j}=\frac{\sum_{m=1}^{l}\left(x_{k i}-\overline{x_{i}}\right)\left(x_{k j}-\overline{x_{j}}\right)}{\sqrt{\sum_{m=1}^{l}\left(x_{k i}-\overline{x_{i}}\right)^{2} \sum_{k=1}^{n}\left(x_{k j}-\overline{x_{j}}\right)^{2}}}
$$

Because $\mathrm{R}$ is a real symmetric matrix (i.e. $\mathrm{rij}=\mathrm{r}_{\mathrm{ji}}$ ), so we only need to calculate its upper triangular element or lower triangular element.

To calculate eigenvalues and eigenvectors

To solve eigenvalue equation $\left|\lambda_{I}-N\right|=0$ for eigenvalue $\lambda_{i}(\mathrm{i}=1,2, \ldots, \mathrm{p})$, and put them in order of magnitude as $\lambda_{1} \geq \lambda_{2} \geq \ldots \geq \lambda_{p} \geq 0$; and then to get the eigenvector $e_{i}(\mathrm{i}=1,2, \ldots, \mathrm{p})$ corresponding to the eigenvalue $\lambda_{i}$.

To calculate principal component contribution rate and cumulative contribution rate Contribution rate of principal component $S_{i}$ :

$$
s_{i}=\frac{r_{i}}{\sum_{k=1}^{q} \gamma_{k}}(i=1,2,3, \ldots, p)
$$

Cumulative contribution rate:

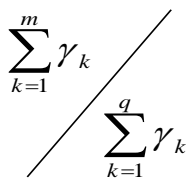

Generally take eigenvalues of main components corresponding to the cumulative contribution rate between 85$95 \%$ and put them in order - first, second,..., $\mathrm{m}(m \leq p)$.

To calculate principal component load

$$
p\left(s_{k}, x_{i}\right)=\sqrt{\gamma_{k}} e_{k i}(i, k=1,2, \ldots, p)
$$

The principal component score can be further calculated:

$$
S=\left\{\begin{array}{llll}
s_{11} & s_{12} & \ldots & s_{1 m} \\
s_{21} & s_{22} & \ldots & s_{2 m} \\
. . & . . & . . & . . \\
s_{n 1} & S_{n 2} & \ldots & s_{n m}
\end{array}\right.
$$

According to the previous standardized data, we put figure of each sample into the equation and get new data of principal component for each sample respectively, or so-called principal component scores. And then the preliminary analysis on information of original variables can be obtained through the analysis of the principal component scores.

\subsubsection{Results of Principal Component Analysis}

When doing principal component analysis, we must first carry out KMO test and Bartlett test, which is the applicable conditions of the principal component analysis. KMO is the indicator to check the sample adequacy, which should be generally greater than 0.5 . SPSS is used here for data processing, and KMO and Bartlett test results are shown in the following table.

Table 4 KMO and Bartlett's Test

\begin{tabular}{|l|l|l|}
\hline \multicolumn{2}{|l|}{ Kaiser-Meyer-Olkin Measure of Sampling Adequacy. } & 0.690 \\
\hline Bartlett's Test of Sphericity & Approx. Chi-Square & 84.789 \\
\cline { 2 - 3 } & df & 15 \\
\cline { 2 - 3 } & Sig. & 0.000 \\
\hline
\end{tabular}

The spherical Bartlett test is to test whether the correlation matrix is a unit matrix, which indicates whether the factor model is appropriate. Through the Bartlett test, it is showed that Bartlett value is 84.798 and $\mathrm{P}$ is smaller than 0.0001 , which means the correlation matrix is not a unit matrix, so factor analysis should be considered. The value of KMO is 0.690 which is smaller than 0.5 , indicating that factor analysis results are acceptable based on the statistical test.Correlation coefficient matrix eigenvalue and variance contribution rate of each factor. To input the data into SPSS, and after rotation, the figures of factors are as follow:

DOI: 10.9790/487X-1901052026 www.iosrjournals.org $23 \mid$ Page


Table 5: Total Variance Explained

\begin{tabular}{|l|l|l|l|l|l|l|}
\hline \multirow{2}{*}{ Component } & \multicolumn{3}{|l|}{ Initial Eigenvalues } & \multicolumn{3}{l|}{ Extraction Sums of Squared Loading } \\
\cline { 2 - 7 } & Total & $\%$ of Variance & Cumulative \% & Total & \% of Variance & Cumulative \% \\
\hline 1 & 4.807 & 80.116 & 80.116 & 4.807 & 80.116 & 80.116 \\
\hline 2 & 1.066 & 17.772 & 97.888 & 1.066 & 17.772 & 97.888 \\
\hline 3 & 0.105 & 1.752 & 99.64 & & & \\
\hline 4 & 0.016 & 0.26 & 99.899 & & & \\
\hline 5 & 0.003 & 0.058 & 99.957 & & & \\
\hline 6 & 0.003 & 0.043 & 100 & & \\
\hline
\end{tabular}

In Table-5 cumulative contribution rate of the first two common factors has reached $97.888 \%$, so it can represent the change of the correlation variables of the whole sample, and the cumulative contribution rate of the first principal component has reached $80.116 \%$.

Table 6: Communalities

\begin{tabular}{|l|l|l|}
\hline & Initial & Extraction \\
\hline Transportation & 1 & 0.988 \\
\hline Visiting & 1 & 0.98 \\
\hline Accommodation & 1 & 0.989 \\
\hline Catering & 1 & 0.954 \\
\hline Merchandise Sales & 1 & 0.993 \\
\hline Entertainment & 1 & 0.968 \\
\hline Extraction Method: Principal Component Analysis. \\
\hline
\end{tabular}

According to Table-6, the common variance of each index variable is greater than 0.9 , which means that these two common factors can practically reflect the most information of the original index variables.

Table 7: Component Matrix

\begin{tabular}{|l|l|l|}
\hline \multirow{2}{*}{} & Component \\
\cline { 2 - 3 } & 1 & 2 \\
\hline Transportation & 0.994 & 0.012 \\
\hline Visiting & 0.99 & -0.013 \\
\hline Accommodation & 0.995 & 0.011 \\
\hline Catering & 0.975 & 0.069 \\
\hline Commodity Sales & 0.288 & 0.954 \\
\hline Entertainment & 0.904 & -0.389 \\
\hline Extraction Method: Principal Component Analysis. \\
\hline 2 components extracted. \\
\hline
\end{tabular}

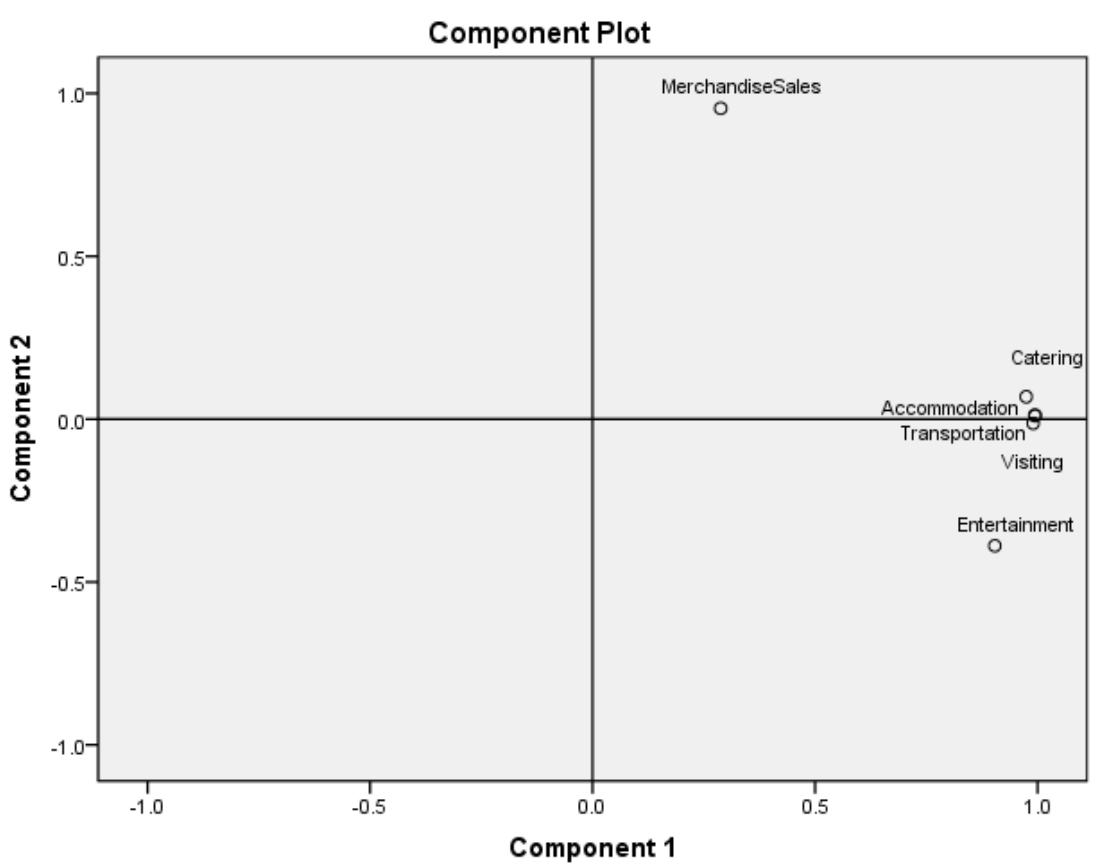

Figure1: Principal Component Plot 
According to Table-7 and Figure-1, the first principal component has a greater positive load in traffic, sightseeing, accommodation, catering and entertainment, which is positively correlated to the foreign exchange earnings of international tourism industry. The second principal component has a greater positive load in commodity sales, mainly reflecting the condition of tourism consumption.Calculation of the scores of each principal component and the comprehensive score. Each principal component is a linear combination of the original index, so the scores of the two principal components can be calculated according to index of each original coefficient provided by coefficient matrix. Z1 and Z2 represent scores of the two-principal component.

Principal component weight: $W_{i}=\lambda_{i} / \sum_{i=1}^{2} \lambda_{i}$. The result of calculation is shown in table 8:

Table 8: Weight of Principal Factors

\begin{tabular}{|l|l|l|l|l|}
\hline Principal factor(Z) & $\begin{array}{l}\text { Eigenvalue } \\
(\lambda)\end{array}$ & $\begin{array}{l}\text { Contribution } \\
\text { rate }(\%)\end{array}$ & $\begin{array}{l}\text { Cumulative } \\
\text { contribution }(\%)\end{array}$ & $\begin{array}{l}\text { Weight of principal } \\
\text { factor(W) }\end{array}$ \\
\hline First factor & 4.807 & 80.116 & 80.116 & 0.818 \\
\hline Second factor & 1.066 & 17.772 & 97.888 & 0.182 \\
\hline
\end{tabular}

To calculate the comprehensive score of each region (Z) according to the linear weighted summation of weight of each principal factor:

$Z=0.818 Z 1+0.182 Z 2$

Table 9: Evaluation of foreign exchange income of XUAR international tourism industry

\begin{tabular}{|l|l|l|l|l|}
\hline Sector & $\begin{array}{l}\text { The first principal } \\
\text { component }\end{array}$ & $\begin{array}{l}\text { The second principal } \\
\text { component }\end{array}$ & $\begin{array}{l}\text { Comprehensive } \\
\text { result }\end{array}$ & Ranking \\
\hline Accommodation & 0.995 & 0.011 & 0.816 & 1 \\
\hline Transportation & 0.994 & 0.012 & 0.816 & 2 \\
\hline Catering & 0.975 & 0.069 & 0.811 & 3 \\
\hline Sightseeing & 0.99 & -0.013 & 0.808 & 4 \\
\hline Entertainment & 0.904 & -0.389 & 0.669 & 5 \\
\hline Commodity Sales & 0.288 & 0.954 & 0.409 & 6 \\
\hline
\end{tabular}

According to Table-9, it can be seen that during the period of 2006-2014 accommodation, transportation, sightseeing and catering accounted for a larger proportion in XUAR tourism foreign exchange earnings while entertainment and merchandise sales accounted for a relatively small proportion, which shows that the structure of local tourism products is sole without outstanding features that can attract visitors to buy products. The whole product line is relatively backward while the entertainment industry lags. To improve the service and quality of these two sectors is a problem that we must pay attention to.

\section{Results, Conclusion And Recommendations}

After all this research and analysis, we should optimize the industrial structure and improve foreign exchange income. Per the correlation between the various departments of the tourism industry analysis, we can conclude that accommodation $>$ traffic $>$ catering $>$ sightseeing $>$ entertainment $>$ shopping, which means we need to support more for sectors of accommodation, transportation, catering and sightseeing. However, entertainment and shopping does not contribute much to XUAR international tourism, indicating that these departments should be the future focuses industry structure adjustment. Therefore, we should focus product development on entertainment and commodity shopping to improve the tourism market structure, so that the tourism market can gain tremendous development.

The industry cluster district should be built in areas with rich cultural background of XUAR, such as cultures of the Silk Road and ethnic minority groups. Each sector of tourism industry should be developed equally and the dominant sectors such as transportation, accommodation, catering and sightseeing should provide stimulating power to commodity sales and entertainment. Moreover, we should build scenic spots with unique features and enhance attractiveness of them, and therefore scenic spots with rich cultural content, beautiful scenery and nationwide fame will be built in industry cluster district and infrastructure will be improved there to attract more tourists.

The key profitable destinations should be built in areas with good infrastructure, unique features and reputation at home and abroad, such as Kanas, Nalat grassland and old town of Kashgar. We can perform intensive management to these scenic spots and invest more in construction to create a more standardized and complete tourism management mechanism, and then expand to the surrounding clusters of tourism resources to achieve the radiation effect and eventually a large-scale tourism industry area will be built. 
Make the best of correlation effect among each sectors of tourism to achieve the transformation from ticket profit mode to comprehensive profit mode. The clear majority of XUAR tourism companies are small businesses and the market is really small with low efficiency and insufficient abilities of product innovation and market competition risk resistance. Therefore, the most urgent problem now is how to change the development mode, encourage small companies to perform joint management and achieve tourism economy increase with government lead. At the same time, we also need to make full use of related industries and integrate tourism resources to change the traditional income mode of ticket selling to a comprehensive profit system of catering, accommodation, transportation, sightseeing, commodity sales and entertainment. With the coordinated growth of each sector, a profitable industrial chain will be formed eventually.

\section{References}

[1] United Nations World Tourism Organization 2016, Tourism Highlights 2016 Edition.

[2] United Nations World Tourism Organization 2016, World Tourism Barometer 2016, Vol.14.

[3] United Nations World Tourism Organization 2015, Tourism Highlights 2015 Edition.

[4] China Tourism Academy 2016, China inbound tourism development annual report 2016.

[5] Merriam Webster Dictionary, 2017.

[6] Towner, J., \& Wall, G. (1991). History and tourism. Annals of Tourism Research, 18(1), 71-84.

[7] Walton, J. K. (2009). Prospects in tourism history: Evolution, state of play and future developments. Tourism Management, 30(6), 783-793.

[8] Cooper, C., \& Hall, C. M. (2008). Contemporary Tourism. Contemporary Tourism, 347-373.

[9] Dolnicar, S., \& Ring, A. (2014). Tourism marketing research: Past, present and future. Annals of Tourism Research, 47, 31-47.

[10] Volo, S. (2014). Contemporary tourism an international approach: 2nd Edn. Annals of Tourism Research, 45, 190-191.

[11] Battour, M., \& Ismail, M. N. (2016). Halal tourism: Concepts, practises, challenges and future. Tourism Management Perspectives.

[12] Dwyer, L., Edwards, D., Mistilis, N., Roman, C., \& Scott, N. (2009). Destination and enterprise management for a tourism future. Tourism Management, 30(1), 63-74.

[13] Tsiotsou, R., \& Ratten, V. (2010). Future research directions in tourism marketing. Marketing Intelligence \& Planning, 28(4), 533544.

[14] Dwyer, L., Forsyth, P. \& Dwyer, W. 2010. Tourism Economics and Policy. Bristol: Channel View Publications.

[15] Sirakaya,E.,Uysal,M.\& Toepper,L.1995.Measuring the performance of South Carolina`s tourist industry from shift-share analysis:a case study,Journal of travel Research, Vol 1,No 2,pp 55-62.

[16] Statistic Bureau of Xinjiang Uygur Autonomous Region 2006-15, Xinjiang Statistical Yearbook 2006-2015.

[17] China National Tourism Administration 2006-15, The year book of China tourism statistic2006-2015.

[18] John E.Hanke \&Dean Wichern 2014, Business Forecasting..Great Britain.Pearson New International Edition.

[19] Davis,J.C.2003, Statistics and Data Analysis in Geology,New York,John Wiley and Sons. 